Témoigner Témoigner. Entre histoire et mémoire

Getuigen Revue pluridisciplinaire de la Fondation Auschwitz

118 | 2014

Au nom des victimes. Dictature et terreur d'État en Argentine, Chili et Uruguay

\title{
Herinneren en vergeten
}

Oblivion en de deconstructie van de slachtofferfiguur

Uruguay. Victimes du souvenir et de l'oubli. Oblivion et la possibilité de

déconstruire les processus de victimisation

Victims of remembrance and forgetfulness: Oblivion and the potentiality of

deconstructing processes of victimization

\section{Susana Draper}

Traducteur : Antonia García Castro

\section{(2) OpenEdition}

\section{Journals}

Édition électronique

URL : http://journals.openedition.org/temoigner/1103

DOI : $10.4000 /$ temoigner. 1103

ISSN : 2506-6390

Éditeur :

Éditions du Centre d'études et de documentation Mémoire d'Auschwitz, Éditions Kimé

Édition imprimée

Date de publication : 1 octobre 2014

Pagination : 113-119

ISBN : 978-2-84174-674-3

ISSN : 2031-4183

Référence électronique

Susana Draper, « Herinneren en vergeten », Témoigner. Entre histoire et mémoire [Online], 118 | 2014,

Online op 01 octobre 2015, geraadpleegd op 23 octobre 2020. URL : http://journals.openedition.org/ temoigner/1103 ; DOI : https://doi.org/10.4000/temoigner.1103 


\section{URUGUAY}

\section{Herinneren en vergeten}

Oblivion en de deconstructie

van de slachtofferfiguur

$\rightarrow$ Susana Draper

Princeton University

(1) Il verwijs naar het
standardwerk van $E$ Elab

(I) $)$ verwiss naar het
standaardwerk van Elizabe

Jelin (Los trabajos de la memoria,
Buenos Aires: Siglo XXI, 2002)

maar ook naar het onderzoee da de Estudios sobre Memoria van het Instituto de Desarrollo Económico y Social en naad
reeks 'Herinneringen aan de 'epressie'. De eerste delen in die reeks verschenen in 2002 en om het cluster van herinnering en ruimte te onderzoeken.

(2) Susana Draper, 'Making the Past Perceptible: Reflections on the Temporal and Visual
Enframings of Violence in the Memory Museum', Journal of Educational Media, Memory, and
Society $4(2), 2012.94-111$ en De cárceles y museos de la memoria alas, itinerarios artísticos y encuadre de temporalidad problemas
$183-202$. (3) Edda Fabbri, Oblivion,
Havana: Casa de las Américas, ectief van de 'topologie van de herinnering'. De uitdrukking verwijst naar een bepaald discours waarbinnen de herinnering wordt gekoppeld

aan voorstellingen van plaats en ruimte (ik denk aan concrete locaties, musea, breder opgevat en verwijst dan naar het proces waarbij gemeenschappen ontstaan door gedeelde herinneringen. ${ }^{1}$

Mijn onderzoek is gericht op gevangenisverhalen uit Uruguay. In Argentinie is het herinneringswerk rond de repressie vooral toegespitst op de verdwijning van mensen en het netwerk van clandestiene opsluitings- en uitroeiingscentra. In Uruguay daarentegen gaat de aandacht voornamelijk naar de politieke gevangenen. Een groot deel van het Cultureel Centrum en Museum van de Herinnering in Montevideo is dan ook gewijd aan het leven in de gevangenis tijdens de dictatuur. Er worden teksten en kunstwerken van politieke gevangenen tentoongesteld, die de bezoeker een inkijk geven in hun dagelijks bestaan. ${ }^{2}$

Ik wil nu graag inzoomen op teksten die door vrouwen zijn geschreven. De slachtbeelden: enerzijds op de herösche voorstelling van de militant als object of subject van een heldenverhaal (met mannelijke connotaties); anderzijds op het beeld van het weerloze slachtoffer in persoonlijke en emotionele verhalen over lijden en onmacht (met vrouwelijke connotaties). Detegenstelling tussen militanten weerloos slachtoffer is problematisch: niet alleen belet die ons om politiek als mensenrech te beschouwen, maar het verleden wordt zo bovendien op een erg simplistische manier voorgesteld. Mensen waren ofwel energiek en machtig (het waren helden), ofwel waren ze passief en boden geen weerstand. Meestal was de situatie aanzienlij complexer dan deze rolverdeling doet vermoeden. Dat zal blijken uit de analyse van Oblivion, een tekst van voormalig politiek gevangene Edda Fabbri ${ }^{3}$, waarin de auteur ter voorstelt en ingat tegen de bestande binaire logica. We zullen hoe dat proces de enscenering van het verleden beïnvloedt. De schrijfster ontwik- 
kelt een alternatieve kijk op het verleden en weigert mee te gaan in het heroïsche militantenverhaal of het weerloze slachtofferverhaal. Haar tekst geeft een nieuwe betekenis aan de politieke strijd uit het verleden, omdat afstand wordt genomen van de dominante 'mannelijke' visie op de militante geschiedenis.

Zolang men slachtoffers blijft opvoeren als lijdzame subjecten, ontzegt men hen een actieve politieke, historische of maatschappelijke rol. De vraag is dan of gender een invloed heeft gehad op de voorstelling van het slachtoffer in Edda Fabbri's tekst. Graciela Sapriza voerde in 2009 een studie uit over de herinnering van de dictatuur Graciestatur vanuit het standpunt van vrouwen. Ze kwam tot het besluit dat slachtofferverhalen vaak worden 'vervrouwelijkt', terwijl naar 'heroïsche, gevaarlijke of politieke actie in de traditionele zin' eerder wordt verwezen aan de hand van 'elementen uit het mannelijke discours'. ${ }^{4}$ In het algemeen krijgen de actoren in het slachtofferverhaa dus een vrouwelijke connotatie, of ze nu man of vrouw zijn. Een aantal vrouwen die vandaag getuigen over hun ervaringen als politiek gevangene, trekken dat procedé nu in twijfel, zonder evenwel terug te vallen op een heroïsch of episch discours. In de getuigenissen die Sapriza verzamelde, vinden we heel andere scenario's en rollen, en ligt de nadruk veeleer op het dagelijkse leven en de emoties. De kracht van zo'n alternatief gezichtspunt mag men niet onderschatten. Het is via hun kritiek op de clichématige invulling van de slachtofferrol (de hulpeloze vrouw), dat vrouwelijke clichem auteurs nieuwe figuren weten te creëren en een genuanceerder beeld schetsen van
de politieke strijd.

EEN MAATSCHAPPELIJKE CONSTRUCTIE: HET SLACHTOFFER ALS SYMBOOL VAN ONMACHT?

(4) Graciela Sapriza, 'Memorias
de muieres en el relato de la dictadura (Uruguay, 1973-1985)' Deportate, esuli, profughe. Rivista
telematica di studi sulla memoria
femminile 11, 2009, 64-80. (5) Er bestaan nog talrijke andere voorbeelden van
vrouwelije politieke gevan vrouwelijke politieke gevangen
die weigeren de klassieke
slachtofferrol op te nemen die hen wordt opgedrongen door het nationale herinneringsbeleid. V'.
Mariana Tello Weiss, 'La cárcel
del Buen Pastor en Cordoba: un territorio de memorias en disputa', Revista Iberoamerican
del Instituto lberoamericano de del Instituto lberoamericano de
Berlín 10(40), 2010, $145-165$ en
Susana Draper, Afterlives of Susana Draper, Afterlives of in Post-Dictatarshsip Latin America, Pittsburgh: Un
Pittsburgh Press, 2012. tproblematische aspect van de klassieke slachtofferfiguur is juist dat die het idee oproept van een hulpeloos persor. Hom actie te ondernemen of weerstand te bieden. Er is duidelijk nood aan een slachtofferverhaal dat de binaire logica van de 'soden'en de 'setroffenen', de jasers en hun prooien, weet te vermijden. Een micro作, politieke sudie vandegebeurtenissen is alvast een stap in de goede richting - en laat dat nu net de thematiek zijn van Oblivion. De tekst doet ons stilstaan bij proce herinnering en vergeten, en bij onze interpretatie van de slachtofferrol.

Fabbri werd bevrijd in 1985. Bijna twintigjaar later schrijft ze Oblivion, waarmee ze niet alleen getuigt over het leven in de gevangenis, maar ook op een kritische en creatieve manier weergeeft hoe de herinnering wordt gestuurd en de slachtofferfiguur vorm kreeg in de loop der jaren. Het is erg bijzonder dat die reflectie ontstaat tijdens het schrijfproces en bovendien een performatieve kracht heeft. Fabbri's getuigenis verzet zich tegen de automatisatie van de herinnering. Nooit worden de overlevenden op een stereotiepe manier voorgesteld. Integendeel, de auteur stelt ongemaklijke vragen: warom motenwe over ( Kan het verleden een antwoord bieden op vragen uit het heden? Het meest problem

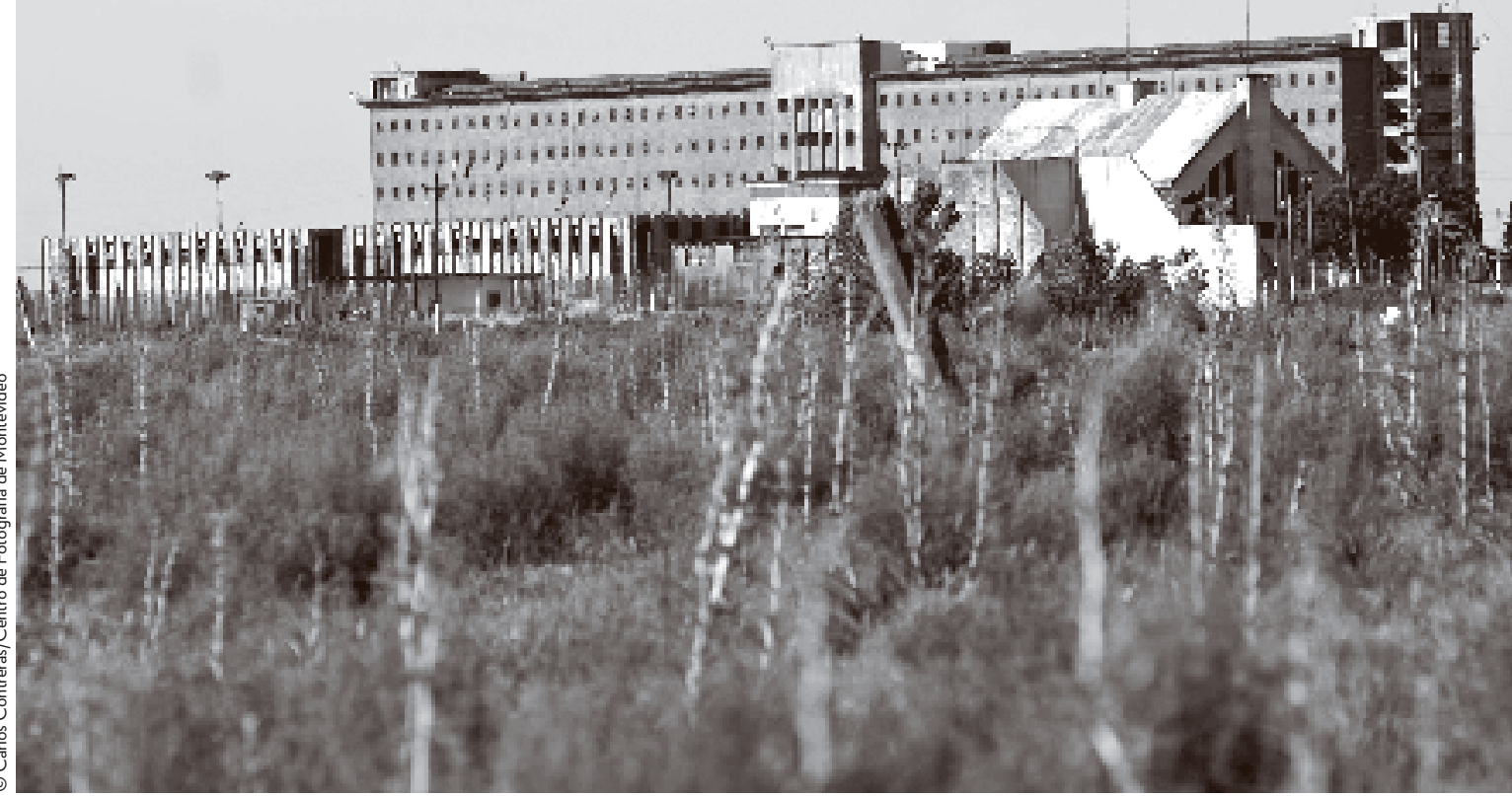

Fabbri was politiek gevangene van 1971 tot de terugkeer naar de democratie. Ze - De gevangenis 'Libertad' ontsnapte uit de Cabildogevangenis samen met 37 andere vrouwen, allemaal militanten van de Tupamaros. ${ }^{6}$ Later kwam ze in de gevangenis van Punta de Rieles terecht en bleef daar opgesloten tot ze amnestie kreeg in 1985. Centraal in haar tekst staat het belang van schrijven voor het herinneringswerk. Tekstuele processen zijn nooit vanzelfsprekend, en moeten telkens in detail ontleed worden: hoe werkt de getuigenis? Hoe biedt de tekst weerstand? Hoe kan schrijven een vorm zijn van verzet?

De titel vat eigenlijk de opzet van het boek samen. Oblivion verwijst naar de moeizame zoektocht van de auteur naar een gepast slachtofferbeeld. De herinnemociz in vo zobbri eden (de gevangene, de militante), maar het is de enige manier om haar oude 'ik' te doen herleven, ondanks de tijd die sindsdien is verstreken en de vele spiegels die nodig zijn om achterom te kijken. Pas toen het verleden ver genoeg achter haar lag, zo vertelt Fabbri tijdens een interview ${ }^{7}$, kon ze aan een literaire carrière beginnen te denken. Toen pas was ze klaar om haar ervaring te reconstrueren en te schrijven over de vrouw die voor haar een vreemde was geworden. Misschien is het precies dankzij de afstand tegenover haar eigen verleden, dat Fabbri de juiste taal vond om het leven in de gevangenis te schetsen, waar het ' ik' zich altijd heeft weggecijferd. ${ }^{8}$

Wanneer ze terugdenkt aan haar gevangenschap, verwijst Fabbri vaak naar de polyfonie van een leven zonder subjectiviteit, zonder ruimte voor het individuele 'ik' Hetleven in de gevangenis is er een van pure trole. Het is bovendien een leven zonder tekst, met uitzondering van de brieven in Montevideo (Uruguay) politinal- hapanaros is een linkse zestig en begin jaren zeventig. (7) Helen Hormilla, 'La memoria
es un derecho, el olvido una capacidad. Entrevista con
Edda Fabbri' La jiribilla Revita


2013, http:///www.lajiribilla.cus articulo/3272//a-memoria-es-un-
derecho-el-olvido-una-capaida (8) Ibid.
(6) De Movimiento de Liberación stadsguerrilla's voerde in de jaren 
die de gevangenen krijgen toegestuurd. De stemmen die we horen in Oblivion, vele jaren later, zijn dan ook die van Fabbri's vriendinnen in de gevangenis: ze lachen, vertellen, dansen en roepen te midden van de waanzin. In de tekst weerklinken de echo's uit het verleden.

Tijdens het interview onderstreept Fabbri verder dat herinnering een recht is, en vergeten een kunst. Dat idee doortrekt de hele tekst en genereert een nieuw en kritisch inzicht in de constructie van de herinnering. De schrijfster hekelt de overan reflectie op de band tussen heden en verleden. De volgende passage is tekenend:

[...] ik weet niet hoe en door wie de geschiedenis wordt geschreven... We grijpen terug naar woorden die we al zo lang kennen, en die hopeloos verouderd zijn. Vroeger zeiden we dat de geschiedenis het verhaal van de winnaars was, en dat we dus een nieuw verhaal moesten schrijven dat meer met de werkelijkheid strookte. We moesten de waarheid vertellen om niet gedoemd te zijn de fouten uit het verleden te herhalen. De erfenis doorgeven voordat we sterven, zo werd ons verteld. Die woorden zeggen me niets; ze zijn op geen enkele manier de mijne, ze klinken hol. Ik heb geen boodschap die ik wil doorgeven, of toch niet dát soortboodschap ('ik weet iets en de ander moet naar me luisteren'). Volgen Fernando Mirza is deju ( The tot histern, zo ts. Ik wil het iet naan we eindelijk eens nadenken over de stilte? Het is tijd dat we ruimte laten voor de stilte, waari vragen van vroeger en nu kunnen weerklinken. Ik heb het al gezegd, en ik zeg het opnieuw: herinneringen vervagen, je raakt ze kwijt. Fló zei: de herinnering is niet de gebeurtenis, maar de sporen ervan. En sporen zijn niet gemaakt van woorden, ze zijn bijna nooit gemaakt van woorden.

Een gangbaar idee - het verleden vertellen opdat de geschiedenis zich niet zou herhalen - wordt in deze passage ontmaskerd als een cliché, en de strijd voor de herinnering (wat ik de 'herinnerinoswending' noem) afgedaan als een ondoordach automatisme. De routineuze formules die we steeds mar herh en, zijn de nach autonation, zijn de melodie van het onzekerheid en pijn. Fabbri wil in haar tekst opnieuw de stilte laten spreken. Z rekent af met de obsessie om het verleden op te rakelen en uit te pluizen, onbeantwoorde vragen telkens opnieuw te stellen, en te blijven speculeren over de mogelijkheid om anders en geweldloos te handelen. Fabbri deconstrueert het slachtofferverhaal en stelt zich vragen over de figuur die naar voren komt in de herinnering van de overlevenden. Op die manier hoopt ze te ontdekken wat de jonge vrouwen werkelijk is overkomen.

In mannelijke teksten lezen we voornamelijk persoonlijke ervaringen van miliIn cenisleven benadrutt ${ }^{10} \mathrm{Het}$ subject verdwijnt nar de achtergrond, de

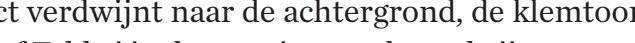
ligt op dat wat men deelt. Het is alsof Fabbri in de ervaring van het schrijven - een
ervaring die ze niet heeft gekend in de gevangenis - een gemeenschappelijke taal zoekt voor de herinnering Het is een feit dat vrouwen in hun teksten vaak de relatie benadrukken tussen taal (een taal die vrouwen van verschillende sociale afkomst delen, ongeacht hun individueel traject), lichaam (seksueel misbruik, bevrijding en morele remmingen), het werk in de gevangenis, moederschap en spel (zingen, toneelspelen). De vrouwen dromen van een gemeenschap waarbinnen ze unieke herinneringen samen kunnen verwerken. Dat is niet geheel onlogisch: de auteurs behoren immers tot de eerste generatie vrouwen die massaal politieke actie heeft ondernomen, en hun traject is daarom gelijklopend.

Taal wordt zo een rustpunt, maar ook een ruimte voor reflectie op alles wat niet met het militantisme te maken heeft. De vrouwen spreken over hun lichaam, over het leven, over hun gevoelens: liefde, haat, de afkeer van niet-politieke gevangen, het verlangen te ontsnappen, maar ook de wil om een gemeenschap te creëren waarbinnen ze de meest intieme zaken kunnen delen die men hen heeft willen afnemen in de gevangenis (het kleine gebaar, de lach). ${ }^{11}$

\section{HERINNERING IN DE TEGENWOORDIGE TIJD}

Zowel in Uruguay als in Argentinië zijn er de laatste jaren behoorlijk wat vrouwen die hun ervaringen tijdens de dictatuur hebben neergeschreven. Het onderwerp van die teksten varieert sterk: in sommige gevallen gaat het om persoonlijke getuigenissen, in andere stellen de auteurs die vorm van herinnering juist aan de kaak. genissen, in andere stellen de auteurs die vorm van herinnering juist aan de kaak.
Beatriz Sarlo maakt in Tiempo pasado ${ }^{12}$ een onderscheid tussen de subjectivistische Beatriz Sarlo maakt in Tiempo pasado $o^{12}$ een onderscheid tussen de subjectivistische herinnering enerzijds, en een meer intellectuele conceptualisering en reconstructie van de herinnering anderzijds. ${ }^{13}$ Ik onderschrijf deze indeling niet volledig, omdat ze de klassieke tegenstelling tussen emotie en ratio, tussen subjectiviteit en objectiviteit, verder uitdiept. Integendeel, het is essentieel om de complexiteit van de herinnering en de getuigenis te onderkennen en te thematiseren.

De vertelster in Fabbri's tekst wordt voorgesteld als een onbekend, vreemd persoon. Vele jaren na de feiten tracht de auteur een schrijfstijl te ontwikkelen die haar toelaat zich te bezinnen over de onoverbrugbare afstand tussen nu en toen. De verstreken tijd staat centraal in al haar bespiegelingen en tast de herinnering aan. De enige manier om haar eigen verhaal te kunnen neerschrijven, is volgens Fabbri door er afstand van te nemen. Soms voert ze zichzelf op als personage (de jonge door er afstand van te nemen. Soms voert ze zichzelf op als personage (de jonge vrouw) en spreekt ze over zichzelf in de derde persoon; op andere momenten is ze
verteller en hanteert ze de eerste persoon, maar is de relatie tot haar personage toch verteller en hanteert ze de eerste persoon, maar is de relatie tot haar personage toch vele malen genuanceerder dan die van een onproblematische 'ik'. De thematisering van de verleden tijd in de tekst creëert een spanning tussen heden en verleden, kritisch daglicht worden gesteld. Het verstrijken van de tijd is een narratologisch instrument voor de voorstelling van het verleden, mar het vormt ook een kader waarbinnen Fabbri dat verleden kan evalueren vanuit het heden.

De tekst hekelt bovendien het rigide, gemilitariseerde en strikte regime in de gevangenis. Dat regime werkt een vereenzelviging van de militante ‘zelf' met de
(11) Dit element vinden we terug in bijna alle gevangenisverhalen:
de collectieve dimensie van het verzet in extreem vernederend
situaties Ikverwis naar de situaties. Ik verwijis naar de
documentaires Memorias de mujeres van Virginia Martínez (Montevideo: Buen Cine instantes van Diana) en Sardozo (México DF: Instituto Mexicano de Cinematografía, 2004) we zulke teksten, zoals die van de Mexicaanse Roberta Avendaño Sobre la libertady dorada, 1998) of van Griselda Loprete (Memorias de una presa 2006). In 2010 produceerde een gevangenen de film Buen Pastor. Una fuga de mujeres (Lucía Torres
Matias Herrera. Cordoba: El Calefón). (12) Beatriz Sarlo, Tiempo pasado
Cultura de la memoria giro
subjetivo, Buenos Aires: Siglo

(13) Voorbeelden zijn te vinden
in de teksten van Pilar Calveiro, Pouvoir et disparition. Les Camps de concentration en Argentine. Isabelle Taudière, Parijis: La Fabrique, 2006 en Emilio de pola, La bemba. Acerca del rum Aires: Siglo XXI, 2005. 
'ander' in de hand, terwijl die ander precies als ander erkend zou moeten worden. Het wordt onmogelijk om iemand in vertrouwen te nemen met wie men nochtans de meest intieme ervaringen deelt. Dat aspect van het gevangenisleven komt nie vaak ter sprake in de sterk evoluerende Argentijnse samenleving, waar de aandach voornamelijk uitgaat naar de politieke strijd. Het is een domein dat ondoordringbaar is voor taal, omdat er primaire emoties heersen die niets te maken hebben met de militante praktijk: men geeft zich bloot aan de niet-gepolitiseerde, radicale 'ander'. Laat dat nu net een onderwerp zijn dat vrouwen regelmatig aansnijden in hun teksten. Misschien is het wel de sleutel tot een vernieuwe de jaren, enoper jauwelijks wortge ruimte cre de eenvoulge geor vijheid - waarin vrijheid als mogelijkheid bestaat - en die du de eenvoudige getuigenis ruim overstijgen. Zulke verhalen ontstaan in de leemte van de tekst en bieden een alternatieve kijk op het politieke leven: de politiek wordt opgeschort, opengebroken en bekritiseerd vanuit een gemeenschappelijke taal. Het is in dit verband opmerkelijk dat vrouwelijke auteurs de politiek anders ervaren tijdens en na hun opsluiting. Ze gaan anders denken over hun eigen subjectiviteit, over hun emoties en over de politiek en zijn zich meer bewust van hun vrouwelijkheid dan voordien. Fabbri vertelt:

[...] soms zoek ik aansluiting met het verleden en dan zie ik die jonge vrouw, dan zie ik hoe ze jarenlang steun kreeg van dat onzichtbare netwerk van solidaire handlangsters. Ik heb het nu niet over politiek, want daar spreek ik niet graag over, en ik heb het ook niet over gevoelens. Ik heb het over het feit dat we samenleefden, dat we de dagelijkse beslommeringen en de meest extreme ervaringen deelden. Ik herinner me nog altijd de douche.

Enkele bladzijden verder verklaart Fabbri dat haar verhaal geenszins heroïsch te noemen is:

Het was geen heroïsch leven - het draaide in elk geval niet om heroïsche daden. Er zijn zeker heroïsche dingen gebeurd. Maar dat is niet de essentie, dat zeg ik nogeens duidelijk, dat zijn niet de dingen die maakten dat onze blik ongeschonden bleef. Ik hou van dat woord, want ik geloof echt dat er iets in ons ongeschonden is gebleven. ${ }^{14}$

In deze passage levert de auteur commentaar op de getuigenis als (politiek) epos of subjectivistische herinnering. Het is opvallend dat een tekst over een jonge militante zich buiten elk politiek of emotioneel kader wil plaatsen, terwijl die twee thema's het raamwerk vormen van de meeste slachtoffergetuigenissen. De herinnering en het vergeten liggen aan de basis van dit verhaal, en scheppen ruimte om vandaag te luisteren naar de stemmen uit het verleden. De kracht van Fabbri's kritische reflectie op de slachtofferrol ligt in het feit dat zij de weg vrijmakt voor een tische refle als houding, als handeling en als kritiek:
Ik zou kunnen zeggen dat ik schrijf om niet te vergeten, maar dat is volgens mij niet zo. Er bestaat zoiets als het recht op vergeten. Het recht om de herinnering te wantrouwen. Ik weet niet of we schrijven om te vergeten, of om te onthouden. We schrijven in elk geval tegen iets, tegen iets wat anderen schrijven of verzwijgen. Misschien schrijven we ook tegen onze eigen stiltes, tegen onze bedrieglijke herinneringen. Ik vertrouw mijn herinneringen niet. Onlangs schreef ik nog dat 'Oblivion eigenlijk om vergiffenis gaat' ${ }^{15}$

Omdat Fabbri het concept van de herinnering uitwerkt voorbij haar morele connotaties, en omdat er ruimte wordt gemaakt om te luisteren, weet ze het verleden op een creatieve manier te verbinden met een emotie die niet politiek of sentimenteel is gekleurd. Wanneer de auteur erop wijst dat het verleden niet 'heroïsch' is, ondanks de heroïsche acties die hebben plaatsgevonden, vraagt ze ons in feite een onderscheid te maken tussen de daad en de mogelijkheid, act en potentie. De daad van de herinnering is een recht, maar oblivion (van het Latijnse obliviscor, vergeten) is een mogelijkheid, een kunst die het startpunt kan vormen van een nieuwe dialoog tussen heden en verleden. We moeten bovendien een andere invulling geven aan het subject van de herinnering, en ons afzetten tegen de traditionele visie op het passieve, lijdende en weerloze slachtoffer Oblivion ontwikkelt een nieuwe kijk op een antal gestigmatiseerde figuren in hetherinneringswerk rond de dictaturenvermijdteen gestign ermijdt een moraliserende blik. Fabbri legt de nadruk op de tekst als proces, waarbij betekenis en functie worden geproblematiseerd in het schrijven zelf, en de herinnering word opgevat als constructie. In de theatrale scène die zo ontstaat, worden we als lezer gedwongen om afstand te nemen en na te denken over de manier waarop we naar de slachtoffers kijken. Oblivion reikt een nieuw interpretatiekader aan, een nieuwe achtergrond waartegen wij als buitenstaanders het verleden kunnen begrijpen, en roept vragen op over de nadrukkelijke aanwezigheid van dat verleden vandaag de dag. I 